\title{
Translation and Validation of the Taiwanese Version of the Self-Efficacy for Appropriate Medication Use Scale
}

\author{
Pei-Ti Chen ${ }^{1}$, Tase-Jyy Wang2* \\ ${ }^{1}$ Department of Nursing, Cardinal Tien College of Healthcare \& Management School of Nursing, National Taipei University of \\ Nursing and Health Science, Taiwan \\ ${ }^{2}$ School of Nursing, National Taipei University of Nursing and Health Science, Taiwan \\ Email: bettyok@ctcn.edu.tw, *tsaejyy@ntunhs.edu.tw
}

How to cite this paper: Chen, P.-T. and Wang, T.-J. (2017) Translation and Validation of the Taiwanese Version of the SelfEfficacy for Appropriate Medication Use Scale. Open Journal of Nursing, 7, 28-38. http://dx.doi.org/10.4236/ojn.2017.71003

Received: December 14, 2016

Accepted: January 10, 2017

Published: January 13, 2017

Copyright $\odot 2017$ by authors and Scientific Research Publishing Inc. This work is licensed under the Creative Commons Attribution International License (CC BY 4.0).

http://creativecommons.org/licenses/by/4.0/

\begin{abstract}
Aims and Objectives: To translate and validate a Taiwanese version of the Self-Efficacy for Appropriate Medication Use Scale (SEAMS). Background: The major barrier in the management of atrial fibrillation is the lack of selfefficacy to medications adherence. Patients' knowledge of the nature of atrial fibrillation and cardiovascular, cerebrovascular risk factors and anticoagulants is a significant factor affecting individuals' adherence. However, few instruments have been developed to assess patients' self-efficacy to medications adherence and none has been translated into Taiwanese. Design: This study used a standard "forward-backward" procedure, which was used to translate SEAMS into Taiwanese language. Reliability was tested for internal consistency. Validity was confirmed by computing a content validity index. Methods: Data collection for this research occurred from October 13, 2015 to October 26, 2016. The sample included atrial fibrillation outpatient. Participants simultaneously completed the Taiwanese version of the Self-Efficacy for Appropriate Medication Use Scale (SEAMS-T). A total of 151 individuals completed the questionnaire. Results: Coefficient alpha was 0.931 for atrial fibrillation patients. Conclusions: Findings provide support for the validity of the Taiwanese version of the Self-Efficacy for Appropriate Medication Use Scale (SEAMS-T). Relevance to Clinical Practice: The translation and validation of an instrument evaluating the self-efficacy for medication adherence in atrial fibrillation contribute to assessing the provided educational intervention.
\end{abstract}

\section{Keywords}

Atrial Fibrillation, Adherence, Self-Efficacy 


\section{Introduction}

Atrial fibrillation is the most common type of arrhythmia [1] [2]. In the adult population of the world, the lifetime risk of atrial fibrillation probability is around $20 \%-25 \%$, which is similar to the white and the Chinese [3]. According to the recently published 2010 global disease burden study (Burden of diseases Global 2010 study), the estimated global prevalence of atrial fibrillation was 33.5 million in 2010, including 20.9 million men and 12.6 million women [4] [5] [6]. But these numbers may be underestimated because many asymptomatic atrial fibrillation patients may not be examined [4] [6].

Approximately 2.7 to 6.1 million people are affected by atrial fibrillation in the United States, and this number is expected to increase [7]. People under the age of 65 who suffer atrial fibrillation are about $2 \%$, and people aged 65 or above suffering atrial fibrillation were about $9 \%$. Because atrial fibrillation increases with age and women generally live longer than men, so there are bigger risks for atrial fibrillation in women than men [7].

According to the study of several Asian teams, the prevalence of atrial fibrillation in Asia is about $1 \%$ of the adult population, lower than white people (about 2\%) [8]. Half of the world's population lives in Asia, and the elderly population in Asia has also increased rapidly [9]. Thus, the burden of atrial fibrillation in Asia is bound to become bigger than ever. In 2050, there will be 72 million atrial fibrillation patients in Asia. This number is bigger than that of patients from Europe and the United States [10]. According to the research in Taiwan, the incidence of atrial fibrillation was 1.68 per 1000 people a year in male and 0.76 per 100 people a year in female. The overall prevalence of atrial fibrillation in Taiwanese is $1.4 \%$ in male and $0.7 \%$ in female [11]. The prevalence and incidence of atrial fibrillation increased substantially with age [11].

Atrial fibrillation causes $15 \%$ - $20 \%$ of chances to suffer ischemic strokes [12] [13], which occur when blood flowing to the brain is blocked by a clot or by fatty deposits called plaque in the blood vessel lining [12]. Compared with those without atrial fibrillation, the risk of stroke in patients with atrial fibrillation increased by four to five times, and stroke which is caused by atrial fibrillation is often more severe than other causes of stroke [12]. More than 750,000 hospitalizations occur each year because of atrial fibrillation. The condition contributes to an estimated 130,000 deaths every year. The death rate from atrial fibrillation as the primary or a contributing cause of death has been rising for more than two decades [14].

Compared with patients without atrial fibrillation, atrial fibrillation patients had three to four times risk of stroke in Asia [11] [15] [16]. The annual risk of atrial fibrillation associated stroke in Taiwan has recently been explored. According to the National Health Insurance Research Database of the whole Taiwanese population, the annual risk of stroke of 185,570 atrial fibrillation patients did not receive any antiplatelet or oral anticoagulant [17].

Atrial fibrillation increases an individual's risk of stroke, heart failure, and other heart-related complications [7] [12]. According to the data from Taiwan 
Stroke Registry, only $28.28 \%$ of people with atrial fibrillation take warfarin, but there are as high as $90 \%$ of patients who meet the criterion and need to take warfarin [18]. The usage of the new oral anticoagulants (e.g. dabigatran, rivaroxaban, apixaban) on patients with atrial fibrillation has better pharmacological effect than warfarin does [19]; nevertheless, warfarin is still the standard treatment of oral anticoagulants for the prevention of stroke in atrial fibrillation [19]. In addition, choices for the proper anticoagulation therapy are based on the risks of thrombosis and abnormal bleeding patients will take, and other clinical factors, including the control of warfarin, drug interaction, adherence, safety of different drug dosage, and individual coagulation monitoring, etc. Therefore, providing knowledge of the usage of anticoagulants for patients with atrial fibrillation can enhance their adherence of using anticoagulants.

The reasons why only a small proportion of patients with atrial fibrillation in Taiwan use warfarin include that they are afraid of taking blood tests regularly, and they are tired of coming back to the clinic, taking blood tests, and getting a revised dosage of medication frequently. Also, they are worried about the side effects of medications, using secret recipes for clearing blood vessels from neighbors without authorization, or turning to famous doctors. All these phenomena mentioned above show that patients with atrial fibrillation in Taiwan have poor adherence of treatment. Thus, focusing more attention on finding out what patients need or what they are confused about, and explaining principles of treatment and methods of medication uses to them is the only way to reach effective prevention.

Disease management of patients with atrial fibrillation aims at reducing symptoms and preventing complications associated with atrial fibrillation, and anticoagulants are able to prevent complications related to atrial fibrillation [20]. However, warfarin and other anticoagulants are used less than recommended in clinical guidelines. This under use results from health care provider obstacles and often groundless safety concerns. Additionally, poor adherence to the anticoagulation regiments can also result in increased risk of stroke or abnormal bleeding.

The term "adherence" is defined as "the extent to which a person's behaviortaking medication, following a diet, and executing lifestyle changes, corresponds with agreed recommendations from a health care provider" [21]. WHO points out that adherence is a multidimensional phenomenon formed by the interactions among five factors, including social and economic factors, health care team and system-related factors, condition-related factors, patient-related factors, and therapy-related factors, all of which are explained respectively as follows [21]. Adherence is related to people's knowledge and beliefs of their illness, motivation to manage it, confidence or self-efficacy in their ability to engage in illnessmanagement behaviors, expectations regarding the outcome of treatment, the consequences of poor adherence, and insufficient understanding of the treatment or their illness [21].

In addition to health beliefs, self-efficacy beliefs also motivate an individual to 
adopt a healthy way of living [22] [23]. Hence, here refers to Social Cognitive Theory (SCT) held by Bandura [24], and agrees with the concept of self-efficacy that only when people show confidence in their abilities to make changes can they really make long-term changes that they wish for. This concept enhances the strength of explanation made by health belief model for long-term behavior changes.

The Self-efficacy for Appropriate Medication Use Scale (SEAMS) provides assessment of medication self-efficacy in the object of study's use of anticoagulants [25]. The instrument contains 13 questions, which mainly focusing on the patients' opinions on their medication. It is a Three-Point Likert Scale, in which 3 means "very confident", 2 meaning "somewhat confident", and 1 meaning "not confident". The potential score ranges from 13 to 39, and higher scores indicate higher levels of self-efficacy for medication adherence. Risser, Jacobson and Kripalani tested 436 patients with coronary artery diseases [25]. The test result reveals internal consistency with a Cronbach's alpha of 0.89 and the test-retest reliability of 0.57 . The researcher has gained the approval of translation into Taiwanese from the original author.

The aim of the present study was to validate the SEAMS in Taiwanese adults with atrial fibrillation. The importance of this study is to translate and validate the scale into Taiwanese, since this would provide the applicability and relevance of an instrument in the Taiwan population. Furthermore, scientists will have the ability to design surveys, giving important findings about the role of healthcare system. In addition, the study allows healthcare providers to assess the provided educational intervention.

\section{Methods}

\subsection{Design}

The study design was cross-sectional. This study was undertaken as a part of a study to evaluate an educational intervention, improving adherence to atrial fibrillation among Taiwanese adults. We used the SEAMS which was translated into Taiwanese and was then administered to participants.

\subsection{Participants and Setting}

This study was conducted at two teaching hospitals in Taiwan, from October 13, 2015 to October 26, 2016. They provide health care, emergency treatment for patients with all illnesses and accidents, and primary and advance medical healthcare.

The inclusion criteria for atrial fibrillation were the following: 1) age of 20 and above, 2) be proficient in Mandarin and Taiwanese, 3) the doctor diagnosed patients with atrial fibrillation, and 4) patients who use anticoagulants (warfarin or NOACs) participate. The exclusion criteria for atrial fibrillation were the following: 1) patients diagnosed with mental illnesses, 2) patients with instability and uncontrolled hypertension, 3) patients with heart failure (NYHA stage IV), 4) installed pacemaker, AICD for patients, 5) patients with cardiac surgery in the 
last three months, and 6) patient who only has the last three months was hospitalized for treatment of atrial fibrillation.

\subsection{Data Collection}

\subsubsection{Socio-Demographic Form}

This consisted of six items regarding socio-demographic characteristics of the samples such as age, gender, education level, marital status, economic, and employment status.

\subsubsection{Disease Characteristic Form}

This consisted of four items regarding disease-demographic characteristics of the samples such as atrial fibrillation diagnosis time, CHA2DS2-VASC, HASBLED, and INR.

\subsection{SEAMS}

The Self-Efficacy for Appropriate Medication Use Scale (SEAMS) contains from 13 to 39 . The response were encoded as "not confident $=1$ ", "somewhat confident $=2$ " and "very confident $=3$ ". The score for the 13-item scale ranged from 13 to 39 . Higher scores indicated higher levels of self-efficacy for medication adherence.

\subsection{Instrument Translation}

This research includes the work of translating the SEAMS, which will be translated according to the method of back-translation indicated by Waltz, Strickland, and Lenz et al. [26]. The process is as follows: The work of instrument translation is divided into two steps. The first step of translation includes: 1) forward translation: translating from the original (source) language of the original instruments into a second (target) language. The original language of the original instruments which are referred to in this research is English, so the researcher decides to invite two bilingual experts for translating each instrument into the target language Taiwanese, and then there will be a primary Taiwanese version of each instrument; 2) discussion over Taiwanese version of each instrument: the researcher and the bilingual experts who assist in the work of translation have a discussion over the Taiwanese version of the instruments, and the discussion will focus on finding the expressions that convey the original meanings the most properly and assessing the extent to which the expressions are comprehended in each instrument; 3 ) inspection from the objects of study: objects of study in different education levels are invited to inspect the extent to which the expressions in the instruments are comprehended, and the researcher will make revision; 4) reverse translation: another two bilingual experts are invited to translate the Taiwanese version of the instruments discussed previously into the original language, English, and then the researcher and the bilingual experts will discuss over the reverse translation of the Taiwanese version and the original instruments, comparing the extent of the difference between the meanings from both the original and the translated instruments; 5) pilot tests for each 
Taiwanese version of the instruments: the researcher will invite cardiologists, cardiac registered nurses, registered nurse experts, and patients with atrial fibrillation to have pilot tests for the Taiwanese version of each instrument, in order to test the extent to which the translated expressions in each instrument are comprehended and how much time the tests will take. The final version of the Taiwanese questionnaire was completed and made available for the reliability and validity study.

\subsection{Procedures}

Researchers distributed the demographic questionnaire, the SEAMS-T to patients. The questionnaire takes about $8-10 \mathrm{~min}$ to complete.

\subsection{Evaluation of SEAMS}

Internal consistency reliability: The Cronbach alpha coefficient was calculated to test the reliability of the questionnaire in its entirety.

Content validity: Three content experts rated the item relevance of the scale. Item-level content validity indexes (I-CVIs) and a scale-level content validity index (S-CVI) were computed to provide evidence of content validity. A universal agreement among experts was required for the S-CVI [27] [28].

\subsection{Ethical Approval}

This study was approved by the Ethics of the "Taipei Medical University-Joint Institutional Review Board”. The Ethical approval number is 201505054. The participants in the study were informed about the purpose of the study. All subjects were provided with written consent before participation. The researcher also guaranteed that the documents would be kept confidential.

\subsection{Statistical Analysis}

Descriptive statistics were used to describe socio-demographic and disease characteristics of the patients and their SEAMS-T scores. Percentages and frequencies were used for the categorical variables, while means and standard deviations were calculated for the continuous variables. Internal consistency was assessed using Cronbach's alpha. The significance level was set at $p$-value $<0.05$. All analyses were performed using SPSS version 23.0.

\section{Results}

\subsection{Sample}

The final analysis included 151 patients with atrial fibrillation. The socio-demographic and disease characteristics of the total are shown in Table 1. The mean SD age was $71.98 \pm 8.61$ years; $62.9 \%$ were men. Of the 151 patients with atrial fibrillation, CH2DS2-VASc score was $4.03 \pm 1.64,3$ (2.0\%), 6 (4.0\%) and 142 (94.0\%) were in the low, medium and high risk; HAS-BLED score was $2.85 \pm$ $1.11,60(39.7 \%)$ and $91(60.3 \%)$ were in low and high score; INR was $1.67 \pm 0.75$. 
Table 1. Socio and disease-demographic characteristics $(n=151)$.

\begin{tabular}{|c|c|c|c|c|}
\hline socio and disease demographic & $\mathrm{n}$ & Percentages (\%) & Mean & SD \\
\hline Age & & & 71.98 & 8.61 \\
\hline \multicolumn{5}{|l|}{ Gender } \\
\hline Female & 56 & 37.1 & & \\
\hline Male & 95 & 62.9 & & \\
\hline \multicolumn{5}{|l|}{ Education Level } \\
\hline No formal education & 8 & 5.3 & & \\
\hline Primary school & 43 & 28.5 & & \\
\hline Secondary school & 21 & 13.9 & & \\
\hline High school & 33 & 21.9 & & \\
\hline College or higher & 46 & 30.4 & & \\
\hline \multicolumn{5}{|l|}{ Marital status } \\
\hline Unmarried & 4 & 2.6 & & \\
\hline Married & 125 & 82.8 & & \\
\hline Divorced/Widowed & 22 & 14.6 & & \\
\hline \multicolumn{5}{|l|}{ Economic status } \\
\hline Not enough & 16 & 10.6 & & \\
\hline More enough & 106 & 70.2 & & \\
\hline Profit & 29 & 19.2 & & \\
\hline \multicolumn{5}{|l|}{ Employment status } \\
\hline Full time/Part time & 29 & 19.2 & & \\
\hline Unemployed & 4 & 2.6 & & \\
\hline Retired & 107 & 70.9 & & \\
\hline Another & 11 & 7.3 & & \\
\hline Time of illness (month) & & & 73.97 & 61.06 \\
\hline CH2DS2-VASc score & & & 4.03 & 1.64 \\
\hline Low risk $($ score $=0$ ) & 3 & 2.0 & & \\
\hline Medium risk $($ score $=1)$ & 6 & 4.0 & & \\
\hline High risk (score $\geq 2$ ) & 142 & 94.0 & & \\
\hline HAS-BLED score & & & 2.85 & 1.11 \\
\hline Low risk (score $=1-2$ ) & 60 & 39.7 & & \\
\hline High risk (score $\geq 3$ ) & 91 & 60.3 & & \\
\hline INR & & & 1.67 & 0.75 \\
\hline
\end{tabular}

\subsection{Evaluation of SEAMS}

\subsubsection{Reliability}

Cronbach's alpha test of internal consistency was 0.931 for the SEAMS-T, and its item to total correlation coefficient ranged from 0.584 to 0.781 (Table 2).

\subsubsection{Content Validity}

The S-CVI was 1 for the SEAMS-T and all its I-CVIs were 1 as well, indicating good content validity [27] [28]. 
Table 2. Taiwanese version of the SEAMS reliability test.

\begin{tabular}{ccccc}
\hline & Mean & SD & $\begin{array}{c}\text { Corrected item-total } \\
\text { correlation }\end{array}$ & $\begin{array}{c}\text { Cronbach's alpha } \\
\text { if item deleted }\end{array}$ \\
\hline Question 1 & 2.66 & 0.49 & 0.591 & 0.929 \\
Question 2 & 2.50 & 0.64 & 0.584 & 0.929 \\
Question 3 & 2.74 & 0.49 & 0.710 & 0.926 \\
Question 4 & 2.61 & 0.58 & 0.740 & 0.924 \\
Question 5 & 2.19 & 0.77 & 0.681 & 0.927 \\
Question 6 & 2.70 & 0.53 & 0.673 & 0.927 \\
Question 7 & 2.59 & 0.61 & 0.772 & 0.923 \\
Question 8 & 2.52 & 0.60 & 0.739 & 0.924 \\
Question 9 & 2.34 & 0.77 & 0.724 & 0.925 \\
Question 10 & 2.47 & 0.69 & 0.781 & 0.922 \\
Question 11 & 2.50 & 0.70 & 0.780 & 0.922 \\
Question 12 & 2.41 & 0.71 & 0.658 & 0.927 \\
Question 13 & 2.66 & 0.53 & 0.588 & 0.929 \\
\hline
\end{tabular}

Cronbach's alpha was 0.931 for the total scale with significant intra-class correlation coefficient $(\mathrm{p}<0.001)$.

\section{Discussion}

The main objective of the study was to report the reliability and validity of the translated of SEAMS in a sample of patients with atrial fibrillation people. This study was the first one which translated and validated the 13-item SEAMS into the Taiwanese language. The original SEAMS was tested by Risser et al. [25] on coronary heart disease patients and other comorbid conditions patients, and it was found that the scale was reliable with good predictive validity and sensitivity. In our study the analysis indicated that SEAMS-T had good Cronbach alpha (0.931); however, the result is similar to those of study from Risser et al. (0.89).

Finally, regarding factors affecting the self-efficacy for medication adherence with atrial fibrillation patients, the analysis indicated that socioeconomic and disease characteristics of the sample were not associated with the self-efficacy of medication adherence. More specifically, no correlation was observed among the level self-efficacy of medication adherence and socioeconomic and disease characteristics. The study findings could be explained by the lack of significant variety regarding these characteristics in the sample.

Furthermore, the results are important for health professionals in the development and evaluation of strategies to promote atrial fibrillation patients' positive self-management. Strategies focusing upon self-efficacy enhancement could be provided to atrial fibrillation patients to improve their medication adherence.

\section{Limitation}

The main limitation of our results is that the study was conducted with atrial fibrillation patients making generalization to other diseases difficult. Future study 
can continue to examine the applicability of the SEAMS-T across other populations. Moreover, the present study was not conducted as responsiveness and predictive validity. Further research on these properties is encouraged.

\section{Conclusions}

For the first time in our study, the SEAMS is used and validated in the Taiwanese language. The Taiwanese version is proved to be acceptable to atrial fibrillation patients; it is a simple questionnaire that can be administered by a trained nurse in face-to-face interviews to overcome non-response by those who cannot read. The findings from this validation study indicate that the Taiwanese version of SEAMS is a reliable and valid measure because it shows acceptable reliability and validity.

The psychometric testing and validation of an instrument assessing the medication adherence of atrial fibrillation contribute to assessing the provided educational intervention. Nurses will have the opportunity to amplify their role in patients' education and develop a relationship based on honesty and respect.

\section{Acknowledgements}

We honestly want to thank Dr. Ming-Hsiung Hsieh and Dr. Ju-Chi Liu for his contribution in collection of the data. We would like to thank all participants for reviewing the questionnaire.

\section{Conflicts of Interest}

The authors declare that there are no conflicts of interest.

\section{References}

[1] Chiang, C.E., Wu, T.J., Ueng, K.C., Chao, T.F., Chang, K.C., Wang, C.C., et al. (2016) 2016 Guidelines of the Taiwan Heart Rhythm Society and the Taiwan Society of Cardiology for the Management of Atrial fibrillation. Journal of the Formosan Medical Association, 115, 893-952. https://doi.org/10.1016/j.jfma.2016.10.005

[2] W ann, L.S., Curtis, A.B., Ellenbogen, K.A., Mark Estes III, N.A., Ezekowitz, M.D., Jackman, W.M., et al. (2011) 2011 ACCF/AHA/HRS Focused Updates Incorporated into the ACC/AHA/ESC 2006 Guideline for the Management of Patients with Atrial Fibrillation. Journal of the American College of Cardiology, 57, 223-242.

https://doi.org/10.1016/j.jacc.2010.10.001

[3] Guo, Y., Tian, Y., Wang, H., Si, Q., Wang, Y. and Lip, GY.H. (2015) Prevalence, Incidence, and Lifetime Risk of Atrial Fibrillation in China: New Insights into the Global Burden of Atrial Fibrillation. Chest, 147, 109-119.

https://doi.org/10.1378/chest.14-0321

[4] Chugh, S.S., Havmoeller, R., Narayanan, K., Singh, D., Rienstra, M., Benjamin, E.J., et al. (2013) Worldwide Epidemiology of Atrial Fibrillation: A Global Burden of Disease 2010 Study. Circulation, 129, 837-847. https://doi.org/10.1161/CIRCULATIONAHA.113.005119

[5] Kirchhof, P., Benussi, S., Kotecha, D., Ahlsson, A., Atar, D., Casadei, B., et al. (2016) 2016 ESC Guidelines for the Management of Atrial Fibrillation Developed in Collaboration with EACTS. European Journal of Cardio-Thoracic Surgery, 50, e1-e88. 
https://doi.org/10.1093/ejcts/ezw313

[6] Sanna, T., Diener, H.C., Passman, R.S., Di Lazzaro, V.D., Bernstein, R.A., Morillo, C.A., et al. (2014) Cryptogenic Stroke and Underlying Atrial Fibrillation. The New England Journal of Medicine, 370, 2478-2786.

https://doi.org/10.1056/NEJMoa1313600

[7] January, C.T., Wann, L.S., Alpert, J.S., Calkins, H., Cigrroa, J.E., Cleveland, J.C., et al. (2014) 2014 AHA/ACC/HRS Guideline for the Management of Patients with Atrial Fibrillation: Executive Summary. Journal of the American College of Cardiology, 64, 2246-2280. https://doi.org/10.1016/j.jacc.2014.03.021

[8] Lip, G.Y., Brechin, C.M. and Lane, D.A. (2012) The Global Burden of Atrial Fibrillation and Stroke: A Systematic Review of the Epidemiology of Atrial Fibrillation in Regions outside North America and Europe. Chest, 142, 1489-1498.

https://doi.org/10.1378/chest.11-2888

[9] Tse, H.F., Wang, Y.J., Ai-Abdullah, M.A., Pizarro-Borromeo, A.B., Chiang, C.E., Krittayaphong, R., et al. (2013) Stroke Prevention in Atrial Fibrillation: An Asian Stroke Perspective. Heart Rhythm, 10, 1082-1088.

https://doi.org/10.1016/j.hrthm.2013.03.017

[10] Krijthe, B.P., Kunst, A., Benjamin, E.J., Lip, G.Y.H., Franco, O.H., Hofman, A., et al. (2013) Projections on the Number of Individuals with Atrial Fibrillation in the European Union, from 2000 to 2060. European Heart Journal, 34, 2746-2751. https://doi.org/10.1093/eurheartj/eht280

[11] Chien, K.L., Su, T.C., Hsu, H.C., Chang, W.T., Chen, P.C., Chen, M.F. and Lee, Y.T. (2010) Atrial Fibrillation Prevalence, Incidence and Risk of Stroke and All-Cause Death among Chinese. International Journal of Cardiology, 139, 173-180. https://doi.org/10.1016/j.ijcard.2008.10.045

[12] Mozaffarian, D., Benjamin, E.J., Go, A.S., Arnett, D.K., Blaha, M.J., Cushman, M., et al. (2016) Heart Disease and Stroke Statistics-2016 Update: A Report from the American Heart Association. Circulation, 133, e38-e360. https://doi.org/10.1161/CIR.0000000000000350

[13] Mozaffarian, D., Benjamin, E.J., Go, A.S., Arnett, D.K., Blaha, M.J., Cushman, M., et al. (2016) Executive Summary: Heart Disease and Stroke Statistics-2016 Update: A Report from the American Heart Association. Circulation, 133, 447-454. https://doi.org/10.1161/CIR.0000000000000366

[14] Centers for Disease Control and Prevention, Atrial Fibrillation. www.cdc.gov/dhdsp/data_statistics/fact_sheets/docs/fs_atrial_fibrillation.pdf

[15] Yap, K.B., Ng, T.P. and Ong, H.Y. (2008) Low Prevalence of Atrial Fibrillation in Community-Dwelling Chinese Aged 55 Years or Older in Singapore: A PopulationBased Study. Journal of Electrocardiology, 41, 94-98. https://doi.org/10.1016/j.jelectrocard.2007.03.012

[16] Zhou, Z. and Hu, D. (2008) An Epidemiological Study on the Prevalence of Atrial Fibrillation in the Chinese Population of Mainland China. Journal of Epidemiology, 18, 209-216. https://doi.org/10.2188/jea.JE2008021

[17] Chao, T.F., Liu, C.J., Wang, K.L., Lin, Y.J., Chang, S.L., Lo, L.W., et al. (2014) Using the CHA2DS2-VASc Score for Refining Stroke Risk Stratification in "Low-Risk" Asian Patients with Atrial Fibrillation. Journal of the American College of Cardiology, 64, 1658-1665. https://doi.org/10.1016/j.jacc.2014.06.1203

[18] Hsieh, F.I., Lien, L.M., Chen, S.T., Bai, C.H., Sun, M.C., Tseng, H.P., et al. (2010) Get with the Guidelines-Stroke Performance Indicators: Surveillance of Stroke Care in the Taiwan Stroke Registry: Get with the Guidelines-Stroke in Taiwan. Circulation, 122, 1116-1123. https://doi.org/10.1161/CIRCULATIONAHA.110.936526 
[19] Capranzano, P., Miccichè, E., D’Urso, L., Privitera, F. and Tamburino, C. (2013) Personalizing Oral Anticoagulant Treatment in Patients with Atrial Fibrillation. Expert Review of Cardiovascular Therapy, 11, 959-973. https://doi.org/10.1586/14779072.2013.818819

[20] Camm, A.J., Kirchhof, P., Lip, G.Y.H., Schotten, U., Savelieva, I., Ernst, S., et al. (2010) Guideline for the Management of Atrial Fibrillation. European Heart Journal, 31, 2369-2429.

[21] World Health Organization (2003) Adherence to Long-Term Therapies: Evidence for Action. 1-198. http://apps.who.int/iris/bitstream/10665/42682/1/9241545992.pdf

[22] Strecher, V.J., DeVellis, B.M., Becker, M.H. and Rosenstock, I.M. (1986) The Role of Self-Efficacy in Achieving Health Behavior Change. Health Education Quarterly, 13, 73-91. https://doi.org/10.1177/109019818601300108

[23] Rosentock, I.M., Strcher, V.J. and Becker, M.H. (1988) Social Learning Theory and the Health Belief Model. Health Education Quarterly, 15, 175-183. https://doi.org/10.1177/109019818801500203

[24] Bandura, A. (1977) Self-Efficacy: Toward a Unifying Theory of Behavior Change. Psychological Review, 84, 191-215. https://doi.org/10.1037/0033-295X.84.2.191

[25] Risser. J., Jacobson, T.A. and Kripalani, S. (2007) Development and Psychometric Evaluation of the Self-Efficacy for Appropriate Medication Use Scale (SEAMS) in Low-Literacy Patients with Chronic Disease. Journal of Nursing Management, 15, 203-219. https://doi.org/10.1891/106137407783095757

[26] Waltz, C.F., Strickland, O.L. and Lenz, E.R. (2010) Measurement in Nursing and Health Research. 4th Edition, Springer Publishing Company, New York.

[27] Polit, D.F. and Beck, T. (2006) The Content Validity Index: Are You Sure You Know What's Being Reported? Critique and Recommendations. Research in Nursing \& Health, 29, 489-497.

https://onlinelibrary.wiley.com/doi/abs/10.1002/nur.20147

[28] Burns, N. and Grove, S.K. (2008) The Practice of Nursing Research: Appraisal, Synthesis, and Generation of Evidence. 6th Edition, W.B. Saunders, Philadelphia, PA. 
Submit or recommend next manuscript to SCIRP and we will provide best service for you:

Accepting pre-submission inquiries through Email, Facebook, LinkedIn, Twitter, etc. A wide selection of journals (inclusive of 9 subjects, more than 200 journals)

Providing 24-hour high-quality service

User-friendly online submission system

Fair and swift peer-review system

Efficient typesetting and proofreading procedure

Display of the result of downloads and visits, as well as the number of cited articles Maximum dissemination of your research work

Submit your manuscript at: http://papersubmission.scirp.org/

Or contact ojn@scirp.org 